\title{
Left-sided robotic thoracic duct clipping for chylothorax
}

\author{
Rafael P. Squitieri, MD, and Albert C. DiMeo, MD, Bridgeport, Conn
}

Chylothorax, defined as the leakage of lymphatic fluid into the pleural space, is a result of thoracic duct injury or more commonly can occur spontaneously, secondary to thoracic malignancy. Conservative management is successful only $50 \%$ of the time and includes chest drainage, octreotide, and dietary changes ranging from a low-fat diet to a diet with fat restricted to medium chain triglycerides to complete bowel rest with total parenteral nutrition. Newer percutaneous embolization techniques can be performed with up to $70 \%$ success, but they are limited to centers with experience in these techniques. ${ }^{1}$ More commonly, when conservative management fails, surgical ligation of the thoracic duct via right thoracotomy or right video-assisted thoracic surgery is performed with good success. ${ }^{2}$ Right-sided robotic duct clipping has also been described. ${ }^{3}$ Only 2 reports exist in the literature of successful left-sided video-assisted ligation. ${ }^{4}$ We report the first case of a similar technique using the da Vinci SI surgical robot (Intuitive Surgical Inc, Sunnyvale, Calif) for a left-sided supradiaphragmatic ligation of the thoracic duct.

\section{CLINICAL SUMMARY}

A 60-year-old man with a diagnosis of stage IV adenocarcinoma of the left lower lobe came to the hospital with a large pericardial effusion, moderate left pleural effusion, and impending tamponade. A pleuropericardial window was performed via a left anterior thoracotomy. On postoperative day 3 , the chest drainage changed to higher volume creamy white fluid with triglycerides of $494 \mathrm{mg} / \mathrm{dL}$, and a new diagnosis of chylothorax was made. For 10 days, despite conservative management, daily drainage exceeded $500 \mathrm{~mL}$. Because the drainage was left sided and because of the desire to definitively treat the malignant left pleural effusion, we decided to perform surgery via the left side of the chest.

After induction of general anesthesia with a double-lumen endotrachael tube, $150 \mathrm{~mL}$ of heavy cream was

\footnotetext{
From the Department of Cardiothoracic Surgery, St Vincent's Medical Center, Bridgeport, Conn.

No grants or financial support or other assistance were given and the authors have no affiliation or financial relationship with Intuitive Surgical, Inc, Sunnyvale, Calif. Disclosures: Authors have nothing to disclose with regard to commercial support. Received for publication June 8, 2012; accepted for publication Aug 21, 2012; available ahead of print Oct 5, 2012.

Address for reprints: Albert C. DiMeo, MD, Minimally Invasive Cardiothoracic Surgery, St Vincent's Medical Center, 2800 Main St, Bridgeport, CT 06606 (E-mail: dimeoalbert@yahoo.com).

J Thorac Cardiovasc Surg 2013;145:299-300

$0022-5223 / \$ 36.00$

Copyright (c) 2013 by The American Association for Thoracic Surgery

http://dx.doi.org/10.1016/j.jtcvs.2012.08.052
}

administered via a nasogastric tube. The patient was positioned in the right lateral decubitus position. A robotic posterior side-docking technique was used. All ports were placed in the midaxillary line: a $12-\mathrm{mm}$ camera was placed in the seventh intercostal space and two 8-mm robotic arm ports in the tenth and fourth intercostal spaces. Bipolar Maryland dissectors (Mediflex Surgical Products, Islandia, NY) and Cadiere forceps (Intuitive Surgical) were used. A single 5-mm assistant port was placed in the eighth intercostal space as anteriorly as possible. Carbon dioxide insufflation was used.

The chest was explored, but no obvious leak was identified. The inferior pulmonary ligament was dissected and the lung retracted superiorly and anteriorly by the assistant. The pleura between the aorta and the esophagus was dissected at the base of the diaphragm and the dissection continued toward the right thorax between the posterior aorta and the vertebral bodies. The posterior vagus nerve was seen coursing along the esophagus. With further dissection, the azygos vein was encountered. The thoracic duct, which was clearly distended with white lymphatic fluid, was then identified between the azygos vein and the aorta and was clipped via the assistant port (Figure 1).

A talc pleurodesis was performed to reduce the risk of recurrent malignant effusion. Two $28 \mathrm{~F}$ chest tubes were placed. Immediately postoperatively, the drainage changed to serosanguineous fluid, without any evidence of chyle.

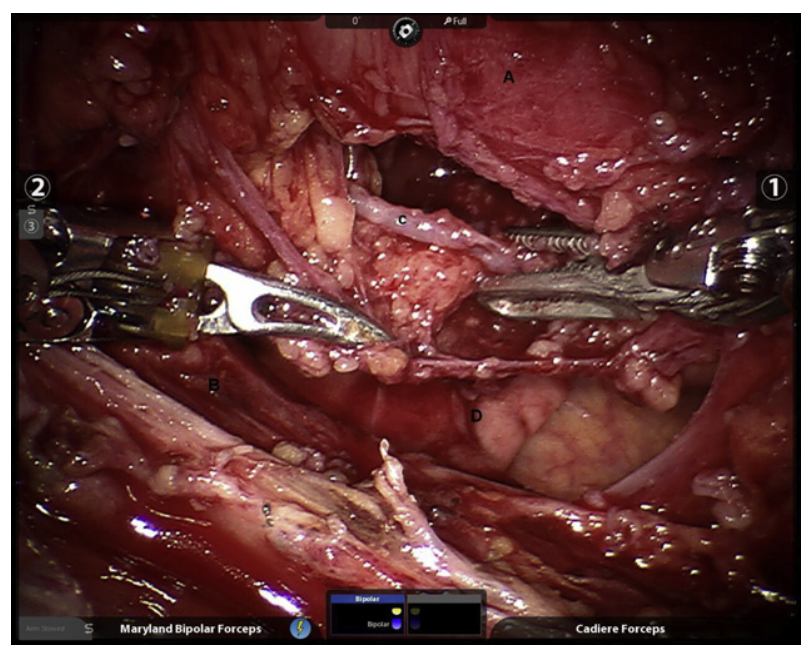

FIGURE 1. Intraoperative view: $A$, Aorta. $B$, Esophagus. $C$, Thoracic duct. $D$, Right lung. 1 is the Cadiere forceps (Intuitive Surgical Inc, Sunnyvale, Calif) and 2 is the Maryland Bipolar dissector (Mediflex Surgical Products, Islandia, NY). 
The tubes were removed on postoperative day 5 , and he was discharged home the same day.

\section{DISCUSSION}

Chylothorax is a very morbid condition in that high-volume drainage causes respiratory compromise and nutritional and immune deficiency. Conservative management has been recommended for up to 2 weeks before attempting surgery, especially in idiopathic cases, but as minimally invasive techniques have improved, early thoracic duct ligation is associated with faster discharge and better recovery with minimal morbidity. ${ }^{5}$ The approach to the duct has traditionally been through the right side of the chest, even in cases of left chylothorax, because the aorta and esophagus overlie the duct from the left. Traditional surgery also emphasizes mass ligation of the tissues between the aorta and the azygos vein because of difficulty identifying the thoracic duct. The robotic platform allows excellent visualization and meticulous dissection, facilitating a transmediastinal approach and direct identification of the thoracic duct.

The advantage of the left-sided approach in cases of left chylothorax is that inspection of the mediastinum can allow identification of small leaking branches that can be directly addressed. If the chylothorax has been caused by leftsided surgery, approaching the duct from the left avoids morbidity and additional pain on the contralateral side. Finally, the ability to approach the duct from either side gives the surgeon more freedom to perform any necessary concomitant procedures. A robotic technique for left-sided surgery for clipping the supradiaphragmatic thoracic duct can be considered for surgical treatment of left-sided chylothorax.

\section{References}

1. Cope C, Kaiser LR. Management of unremitting chylothorax by percutaneous embolization and blockage of retroperitoneal lymphatic vessels in 42 patients. $J$ Vasc Interv Radiol. 2002;13:1139-48.

2. Christodoulou M, Ris HB, Pezzetta E. Video-assisted right supradiaphragmatic thoracic duct ligation for non-traumatic recurrent chylothorax. Eur J Cardiothorac Surg. 2006;29:810-4

3. Thompson KJ, Kernstine KH, Grannis FW, Mojica P, Falabella A. Treatment of chylothorax by robotic thoracic duct ligation. Ann Thorac Surg. 2008;85: 334-6.

4. Watanabe A, Koyanagi T, Nakashima S, Higami T. Supradiaphagmatic thoracic duct clipping for chylothorax through left-sided video-assisted thoracoscopic surgery. Eur J Cardiothorac Surg. 2007;31:313-4.

5. Paul S, Altorki NK, Port JL, Stiles BM, Lee PC. Surgical management of chylothorax. Thorac Cardiovasc Surg. 2009;57:226-8.

\title{
Recurrent catamenial hemopneumothorax treated by coverage with polyglycolic acid sheets
}

\author{
Mamoru Takahashi, MD, ${ }^{\mathrm{a}}$ Tadashi Matsukura, $\mathrm{MD}, \mathrm{PhD},{ }^{\mathrm{a}}$ Takashi Hirai, $\mathrm{MD}, \mathrm{PhD},{ }^{\mathrm{a}}$ and \\ Nobuya Mino, MD, PhD, ${ }^{\mathrm{b}}$ Fukui and Shizuoka, Japan
}

Catamenial hemopneumothorax is a rare disease entity related to thoracic endometriosis in women of reproductive age, and there is limited surgical experience in terms of treatment. ${ }^{1}$ We successfully treated the disorder using coverage with polyglycolic acid (PGA) sheets.

\section{CLINICAL SUMMARY}

A 36-year-old woman, gravida 0 , with an unremarkable medical history presented at Fukui Red Cross Hospital

\footnotetext{
From the Department of Chest Surgery, ${ }^{a}$ Fukui Red Cross Hospital, Fukui, Japan; and Department of Chest Surgery, ${ }^{b}$ Hamamatsu Rosai Hospital, Shizuoka, Japan.

Disclosures: Authors have nothing to disclose with regard to commercial support.

Received for publication May 8, 2012; revisions received Aug 14, 2012; accepted for publication Aug 23, 2012; available ahead of print Sept 17, 2012.

Address for reprints: Mamoru Takahashi, MD, Fukui Red Cross Hospital, 2-4-1

Tsukimi, Fukui City, Fukui, 918-8501, Japan (E-mail: mt10947@yahoo.co.jp).

J Thorac Cardiovasc Surg 2013;145:300-2

0022-5223/\$36.00

Copyright (C) 2013 by The American Association for Thoracic Surgery

http://dx.doi.org/10.1016/j.jtcvs.2012.08.054
}

(Fukui, Japan) for the investigation of asymptomatic right pleural effusion detected during a routine medical checkup. Thoracic computed tomography revealed extensive pleural effusion on the right side; however, no pneumothorax was identified. Moreover, no bullae or lung nodules were detected. We placed a chest drain in the right side of the chest, and the effusion showed an appearance similar to bloody vaginal discharge. The extent of effusion and air leakage appeared to increase during the onset of menstruation. A high level of cancer antigen 125 (2620 $\mathrm{U} / \mathrm{mL}$ ) was detected in a sample of the pleural effusion fluid. The patient then underwent video-assisted thoracoscopic surgery for precise diagnosis and treatment. Intraoperative findings showed numerous blueberry-like spots on the visceral and parietal pleura and the diaphragm (Figure 1, A). Complete resection of the lesions seemed to be difficult, although biopsy samples were collected during the surgery. Pathologic examination revealed endometrial glands embedded in the visceral pleura, parietal pleura, and diaphragmatic muscles (Figure 1,B). These 